Supporting Information for

\title{
Structural Stability of L-cystine under Extreme Conditions
}

Meng Song ${ }^{1}$, Weiwei Li ${ }^{~}$, Xiaoliang Zhang ${ }^{1}$, Junxiu Liu ${ }^{1}$, Kuo Li, ${ }^{2}$ Hengzhong Zhang ${ }^{*}, 1$

${ }^{1}$ Center for High Pressure Science and Technology Advanced Research, Shanghai 201203, China

${ }^{2}$ Center for High Pressure Science and Technology Advanced Research, Beijing 100094, China 

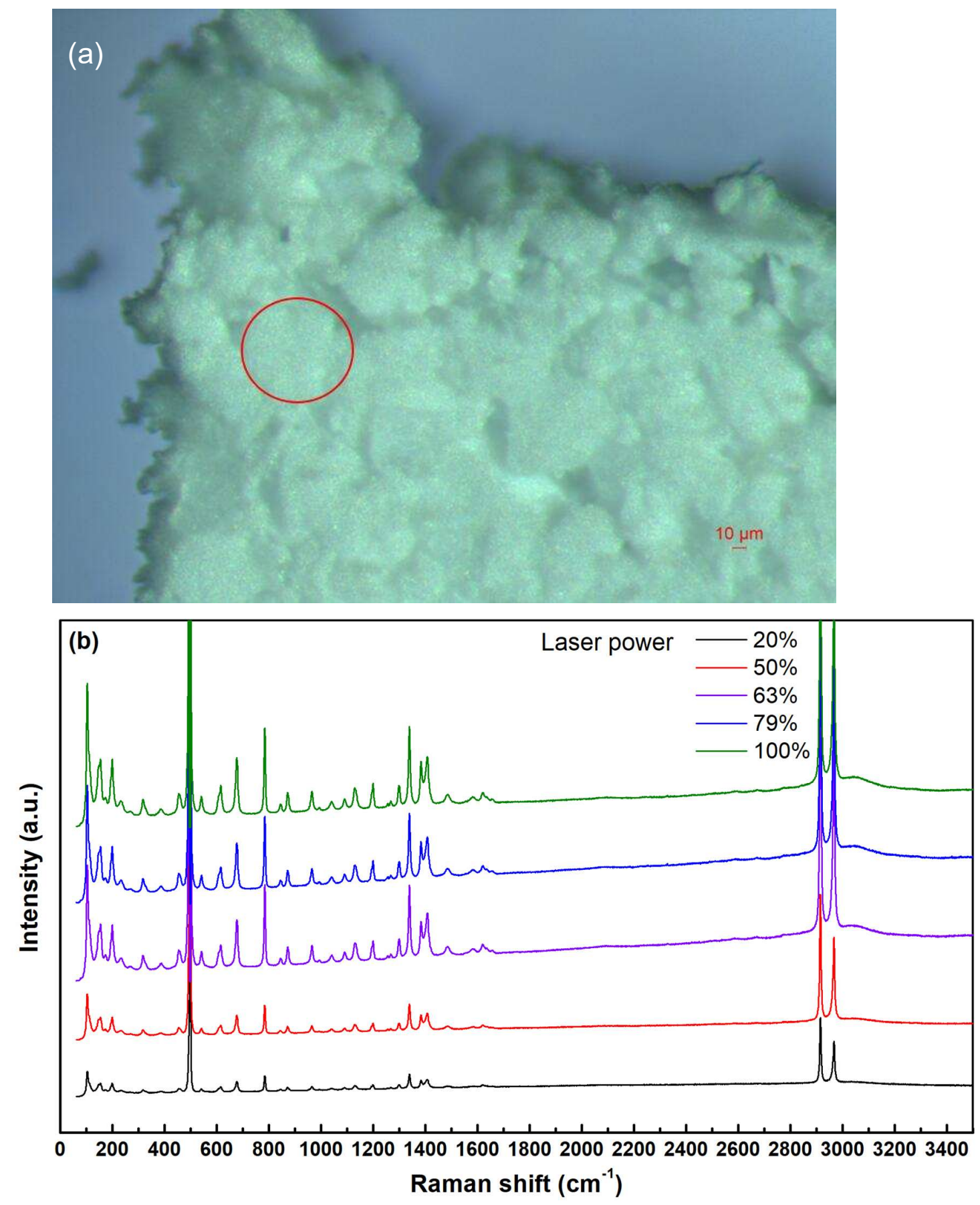

Figure S1. (a), Optical microscopy image of an L-cystine test sample (powders on a glass slide) experienced the Raman measurements at different exciting laser powers $(20-100 \%$ of the full laser power). No apparent sample damage by the laser was observed. (b), Raman spectra of the Lcystine sample at different applied laser powers. A $50 \%$ of the full power was chosen for subsequent measurements. 

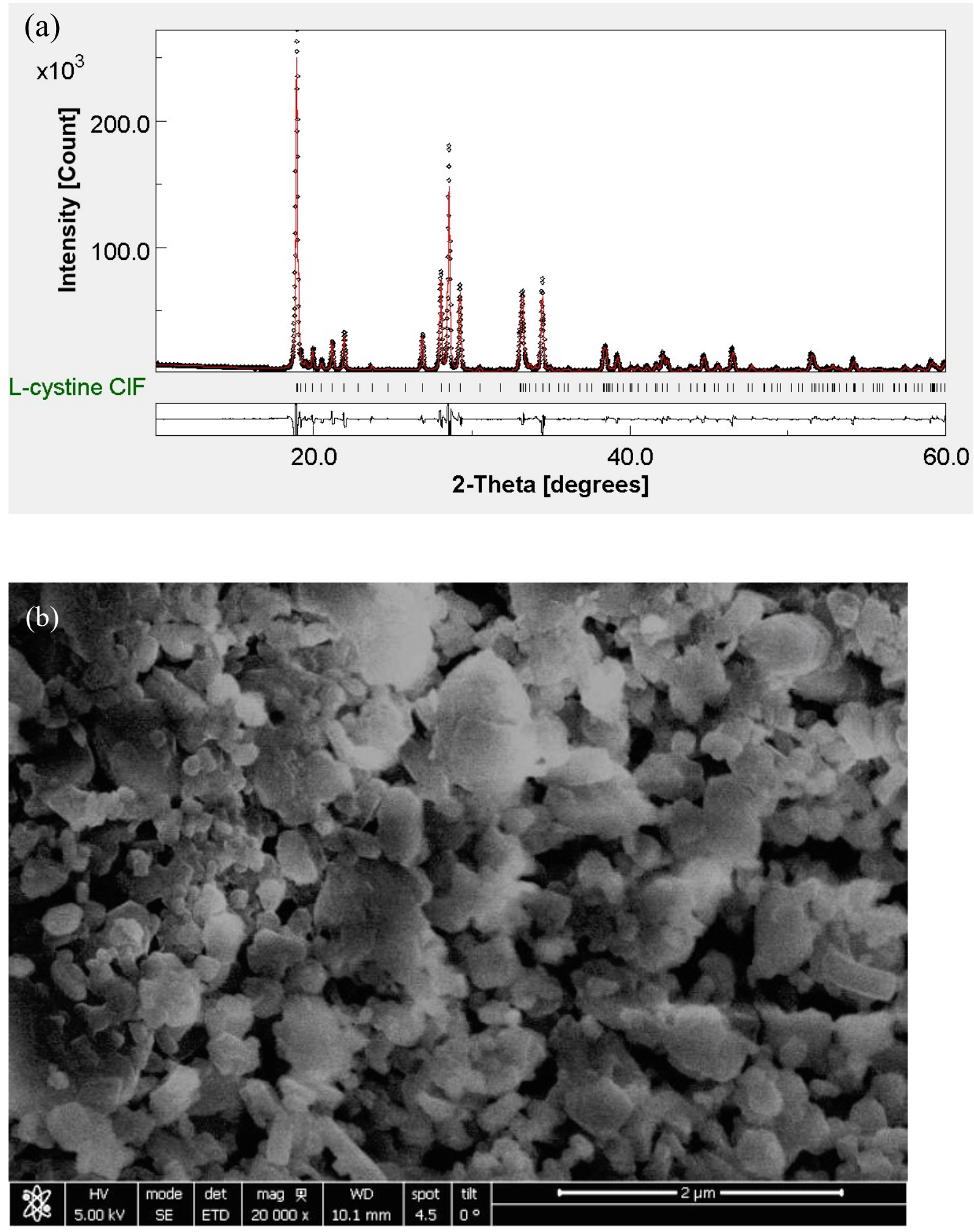

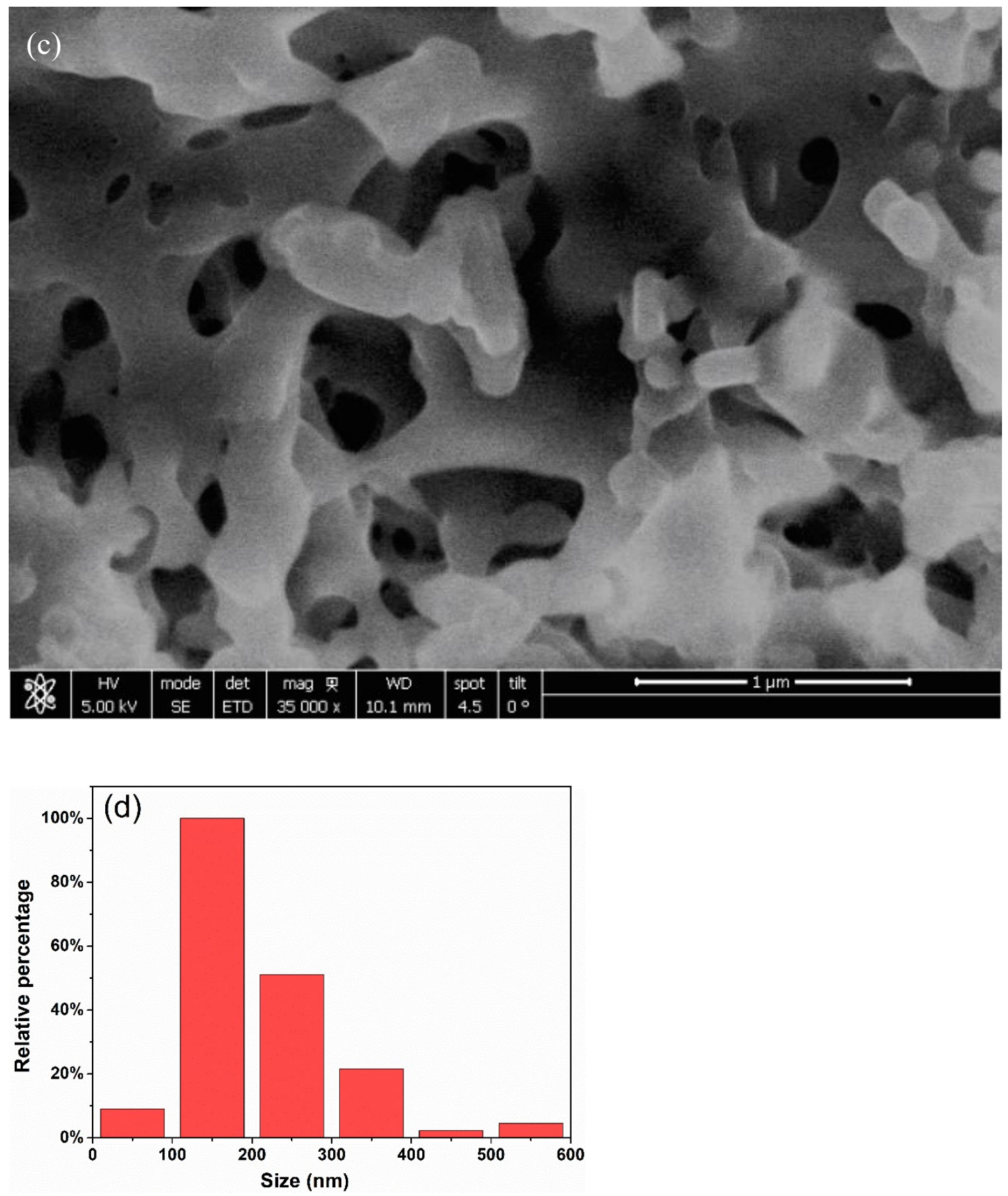

Figure S2. (a), Rietveld fitting of XRD pattern of L-cystine at ambient pressure (X-ray wavelength $1.5406 \AA$ ); SEM images (b - c) and grain size distribution (d) of finely ground L-cystine powders. 
Table S1. Lattice parameters of L-cystine at different pressures derived from Rietveld fitting of the HP-XRD data.

\begin{tabular}{|c|c|c|c|c|c|c|c|}
\hline $\begin{array}{c}\text { Pressure } \\
(\mathrm{GPa})\end{array}$ & $a(\AA)$ & $c(\AA)$ & $\begin{array}{c}\text { Unit cell } \\
\text { volume } \\
\left(\AA^{3}\right)\end{array}$ & $\begin{array}{l}\text { Average } \\
\text { particle } \\
\text { size }(\mathrm{nm})\end{array}$ & Microstrain & $\mathrm{Sig}^{\mathrm{c}}$ & $\begin{array}{c}\mathrm{Rwp}^{\mathrm{c}} \\
(\%)\end{array}$ \\
\hline $\begin{array}{l}0 \text { (ambient } \\
\text { pressure) }\end{array}$ & 5.414 & 56.197 & 1426.3 & $150^{\mathrm{a}}$ & & & \\
\hline 0.4 & 5.3994 & 55.9021 & 1411.4 & 38.2 & 0.0050 & 0.305 & 0.526 \\
\hline 1.2 & 5.3377 & 54.8055 & 1352.3 & 43.4 & 0.0040 & 0.173 & 0.582 \\
\hline 2.8 & 5.2670 & 53.7542 & 1291.4 & 48.5 & 0.0045 & 0.355 & 0.737 \\
\hline 3.9 & 5.2225 & 53.0881 & 1254.0 & 42.6 & 0.0047 & 0.152 & 0.493 \\
\hline 5.8 & 5.1624 & 52.2664 & 1206.3 & 41.3 & 0.0047 & 0.152 & 0.493 \\
\hline 6.6 & 5.1433 & 51.8614 & 1188.1 & 38.6 & 0.0049 & 0.256 & 0.489 \\
\hline 7.7 & 5.1122 & 51.4030 & 1163.4 & 38.9 & 0.0049 & 0.218 & 0.420 \\
\hline 9.1 & 5.0829 & 50.9358 & 1139.6 & 35.9 & 0.0049 & 0.194 & 0.375 \\
\hline 11.0 & 5.0430 & 50.4769 & 1111.7 & 35.4 & 0.0052 & 0.149 & 0.290 \\
\hline 12.8 & 5.0098 & 50.0989 & 1088.9 & 32.8 & 0.0053 & 0.139 & 0.272 \\
\hline 13.9 & 4.9887 & 49.8758 & 1075.0 & 32.0 & 0.0051 & 0.160 & 0.773 \\
\hline 14.8 & 4.9726 & 49.6659 & 1063.6 & 29.7 & 0.0054 & 0.161 & 0.311 \\
\hline 17.2 & 4.9381 & 49.2969 & 1041.1 & 27.5 & 0.0057 & 0.198 & 0.353 \\
\hline 20.5 & 4.8938 & 48.7902 & 1011.9 & 22.6 & 0.0052 & 0.259 & 0.375 \\
\hline $\mathrm{D} 15.5^{\mathrm{b}}$ & 4.9764 & 49.7980 & 1068.0 & 24.4 & 0.0056 & 0.147 & 0.285 \\
\hline D11.0 & 5.0513 & 50.5142 & 1116.2 & 37.9 & 0.0066 & 0.205 & 0.377 \\
\hline D1.8 & 5.3291 & 54.5018 & 1340.4 & 38.7 & 0.0042 & 0.361 & 0.657 \\
\hline D0 & 5.4473 & 56.6584 & 1456.0 & 38.8 & 0.0052 & 0.277 & 0.515 \\
\hline
\end{tabular}

${ }^{\text {a }}$ Most probably distributed grain size in the finely ground sample as estimated from SEM imaging (see Figure S2d).

$\mathrm{b}$ "D" denotes decompression.

c "Sig" and "Rwp" are two fitting tolerance factors, which ought to be less than 2.0 and $8 \%$, respectively, if a fit is considered as satisfactory. ${ }^{1-3}$ 

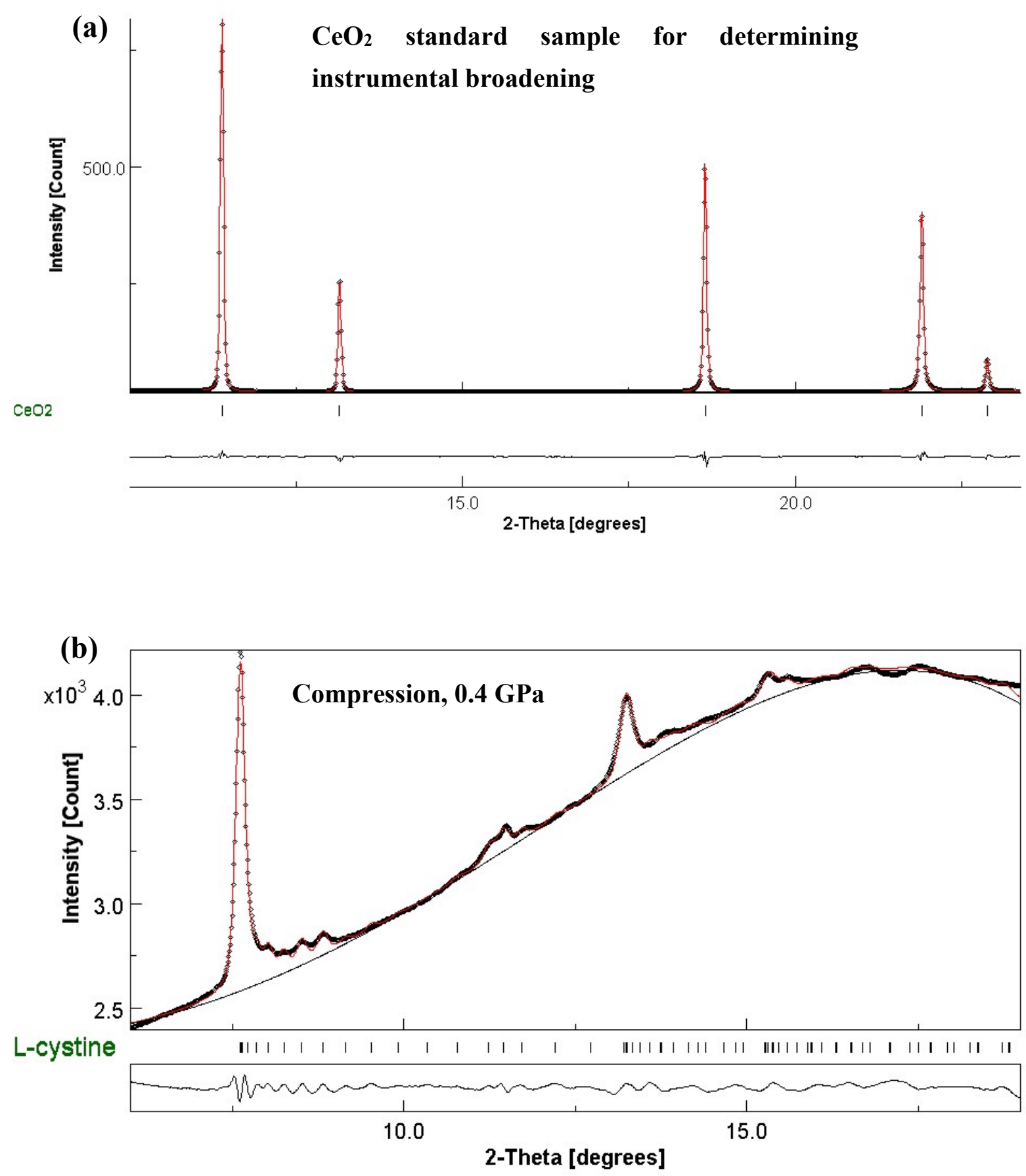

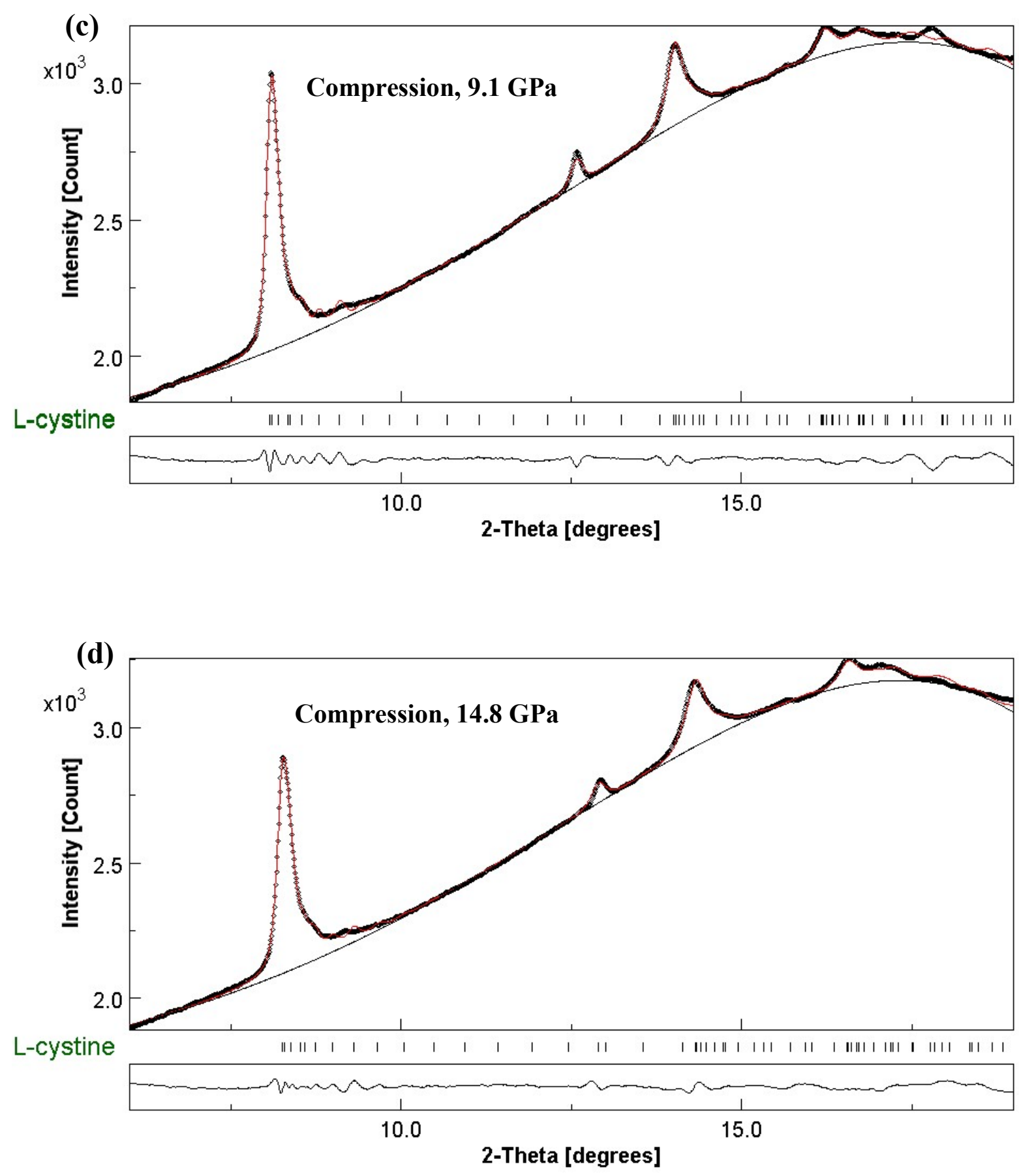

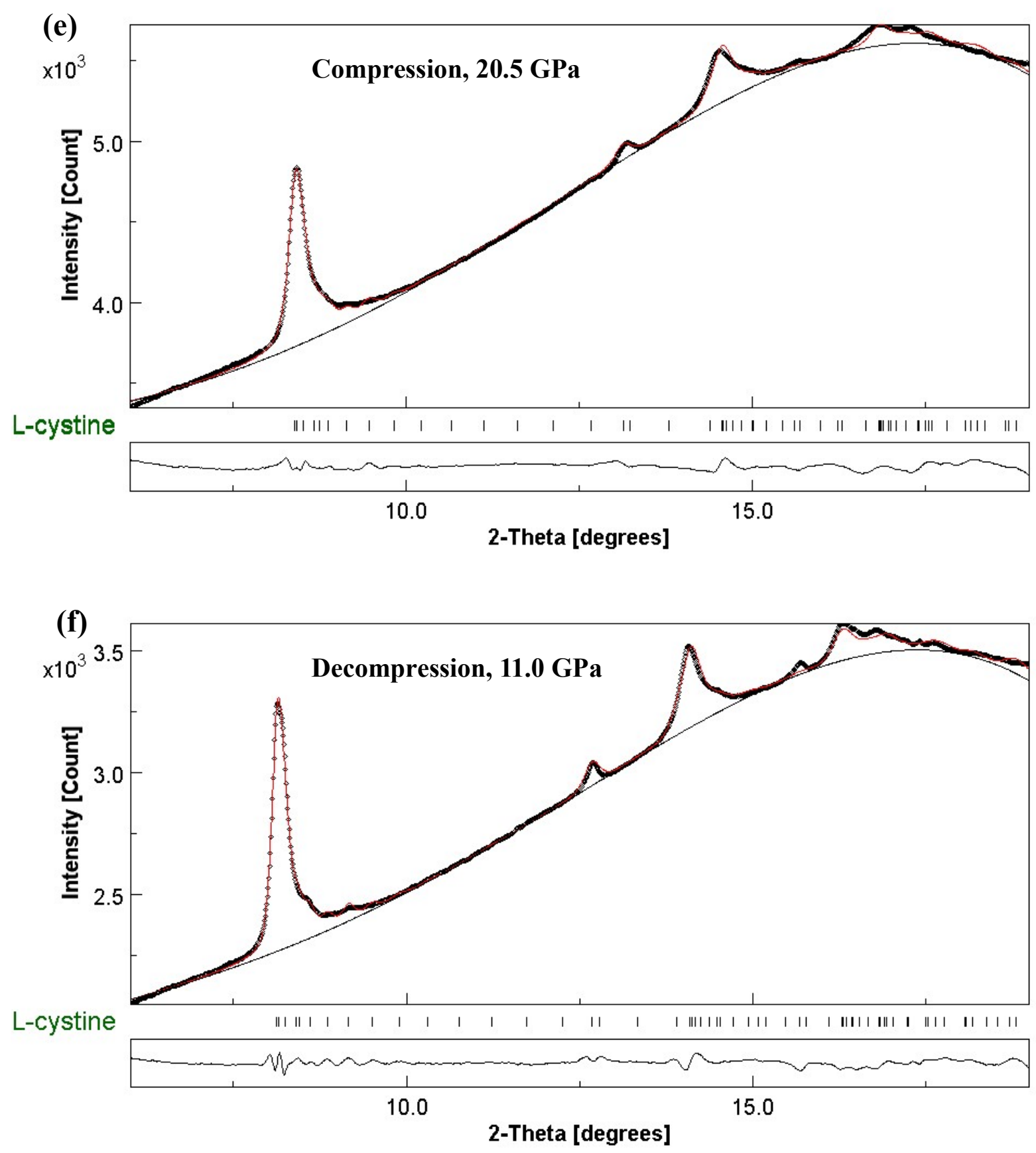


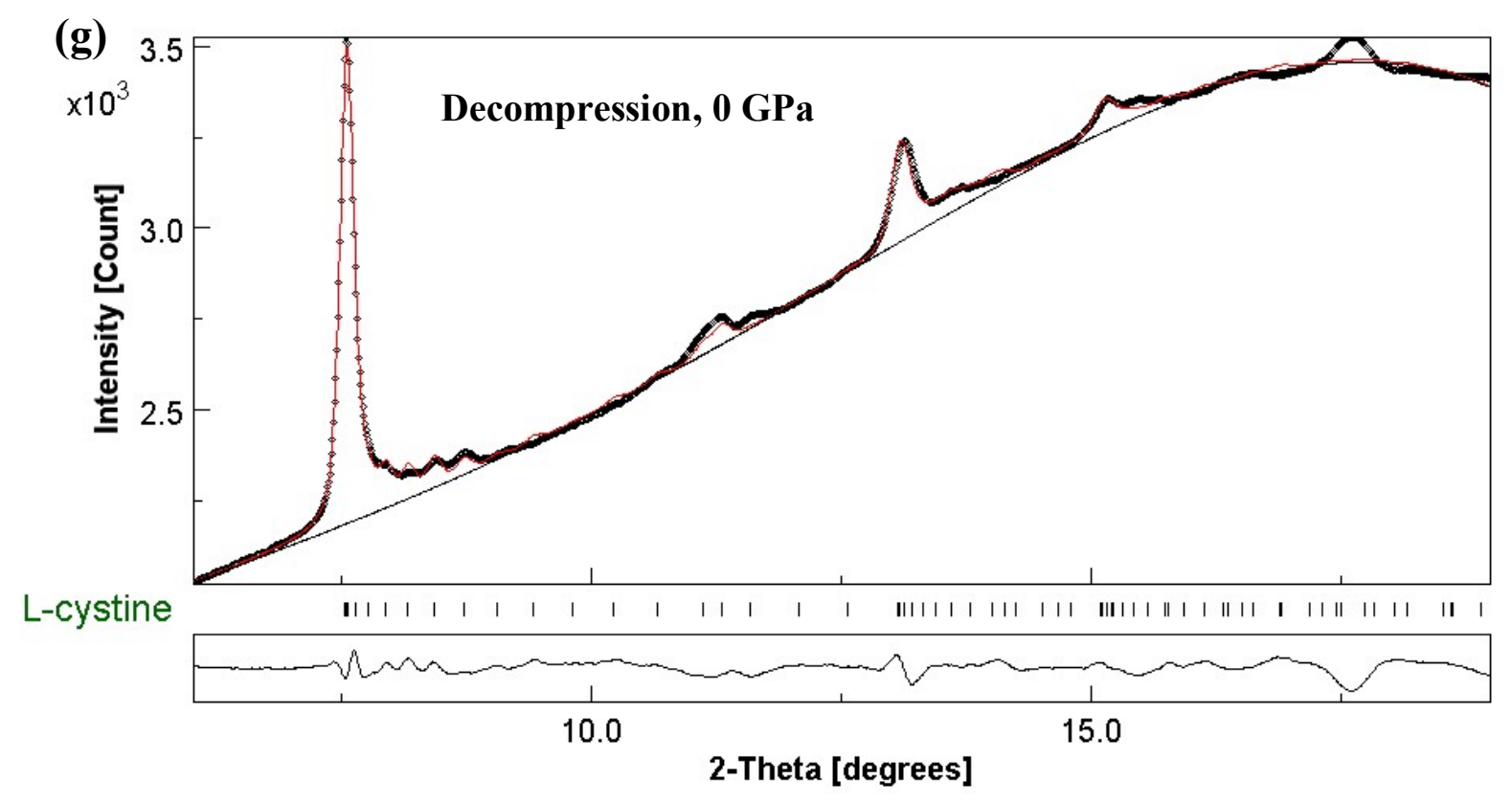

Figure S3. Representative Rietveld fitting of XRD patterns of a $\mathrm{CeO}_{2}$ standard (a) and L-cystine at chosen pressures in compression ( $\mathrm{b}-\mathrm{e}$ ) and decompression ( $\mathrm{f}-\mathrm{g}$ ). The X-ray wavelength is $0.6199 \AA$. The red lines are the fittings using a hexagonal L-cystine structure (COD file \#15133284). The short vertical bars represent the peak positions from the fitting and the curve boxed at the bottom shows the difference between the fitting and the experimental data. 

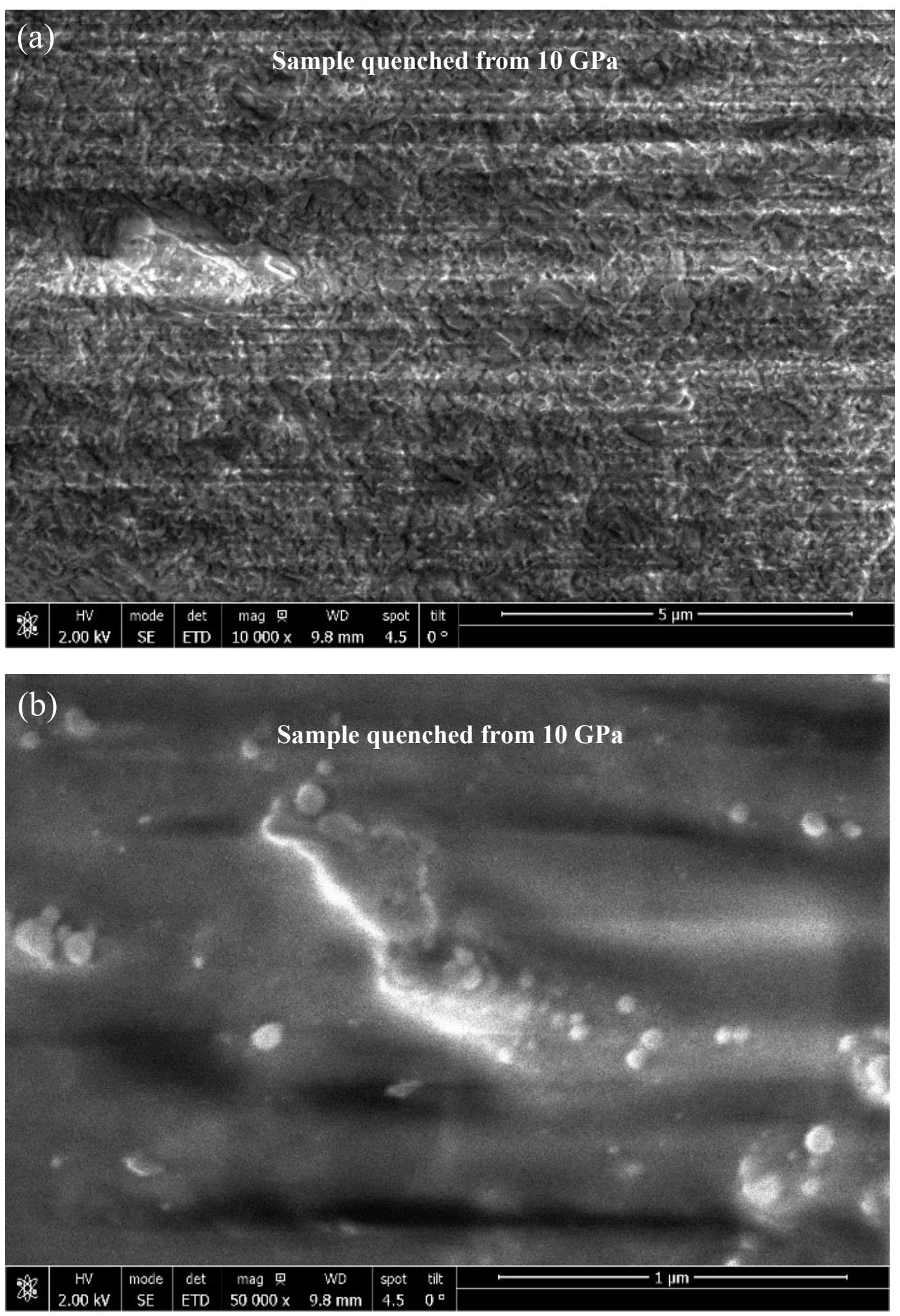


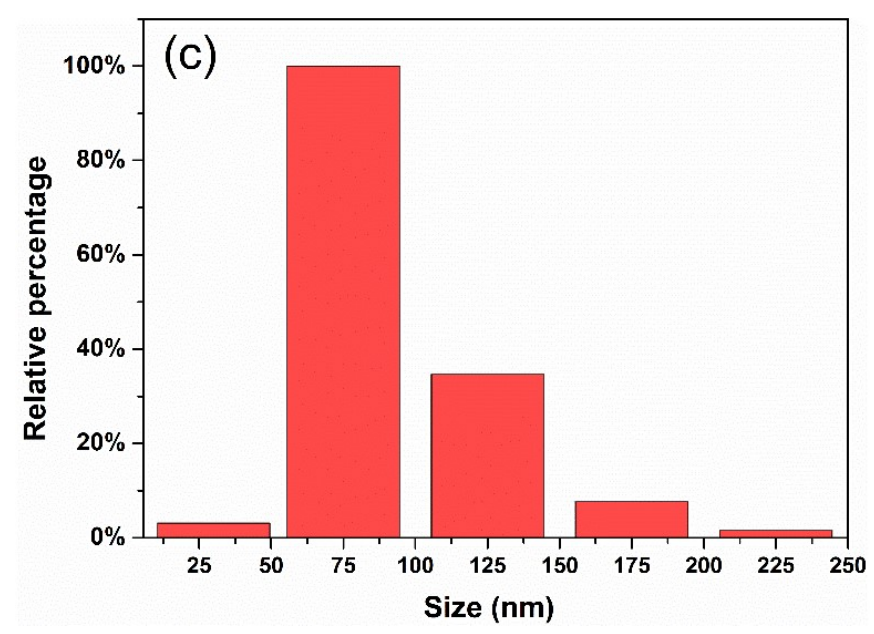

Figure S4. SEM images (a - b) and grain size distribution (c) of L-cystine after quenching from compression to $\sim 10 \mathrm{GPa}$. In (c), only visually discernable particles were counted.

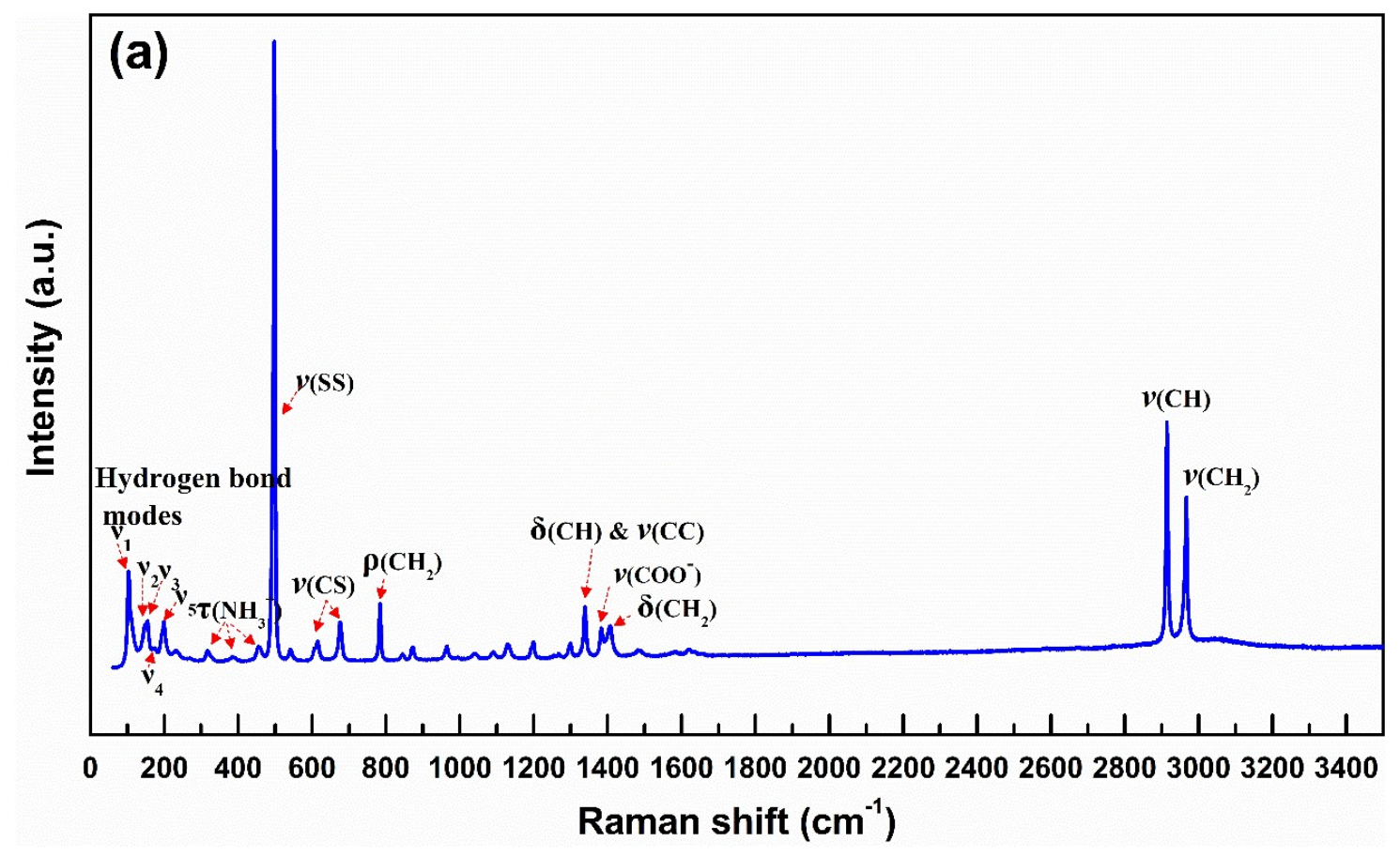




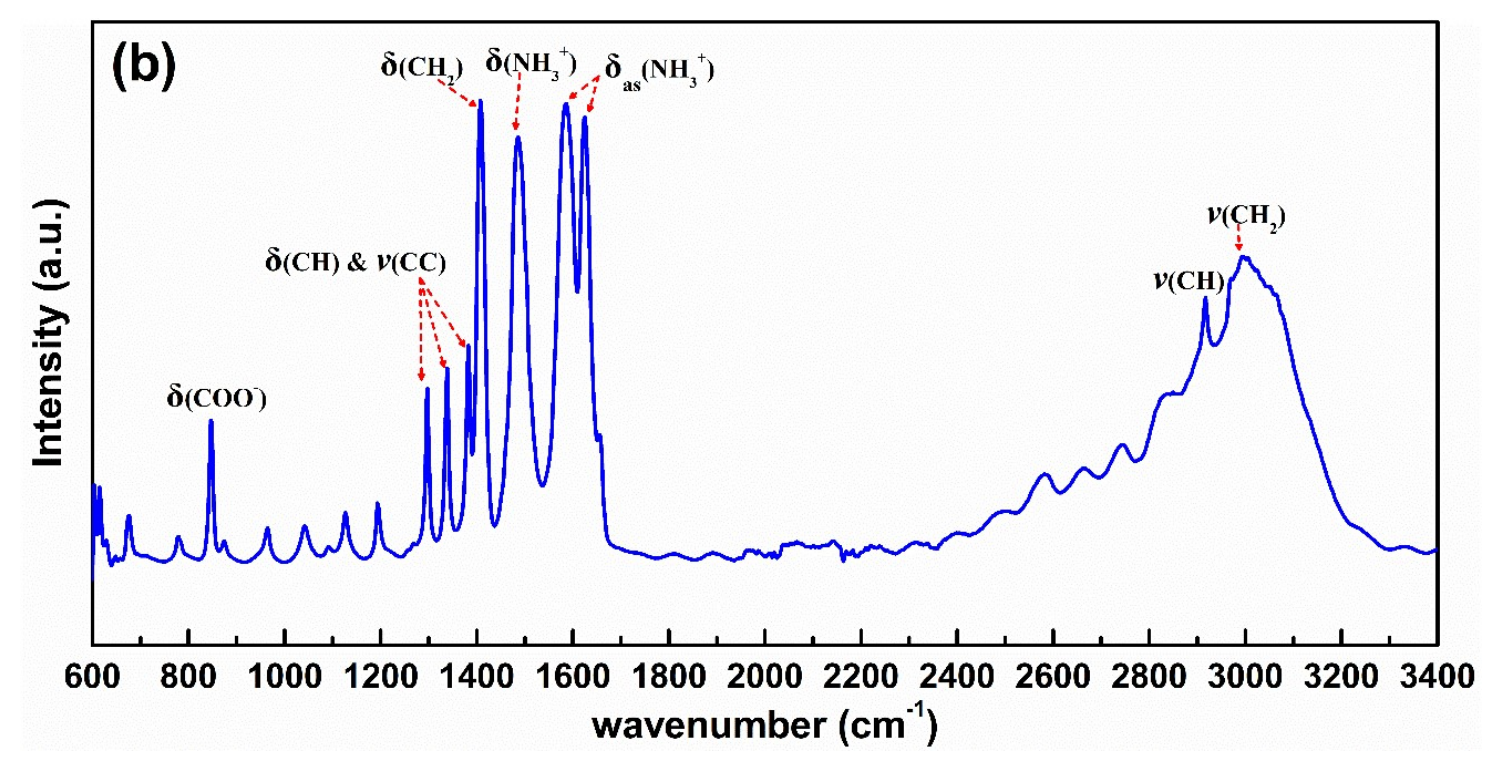

Figure S5. (a), Raman spectra of L-cystine at ambient condition (measured on a glass slide). (b), Infrared absorbance spectra of L-cystine at ambient condition (measured in a DAC). Symbols denoting vibrational mode: $v$, stretch; $\tau$, torsion; $\delta$, bend; $\rho$, rock. 


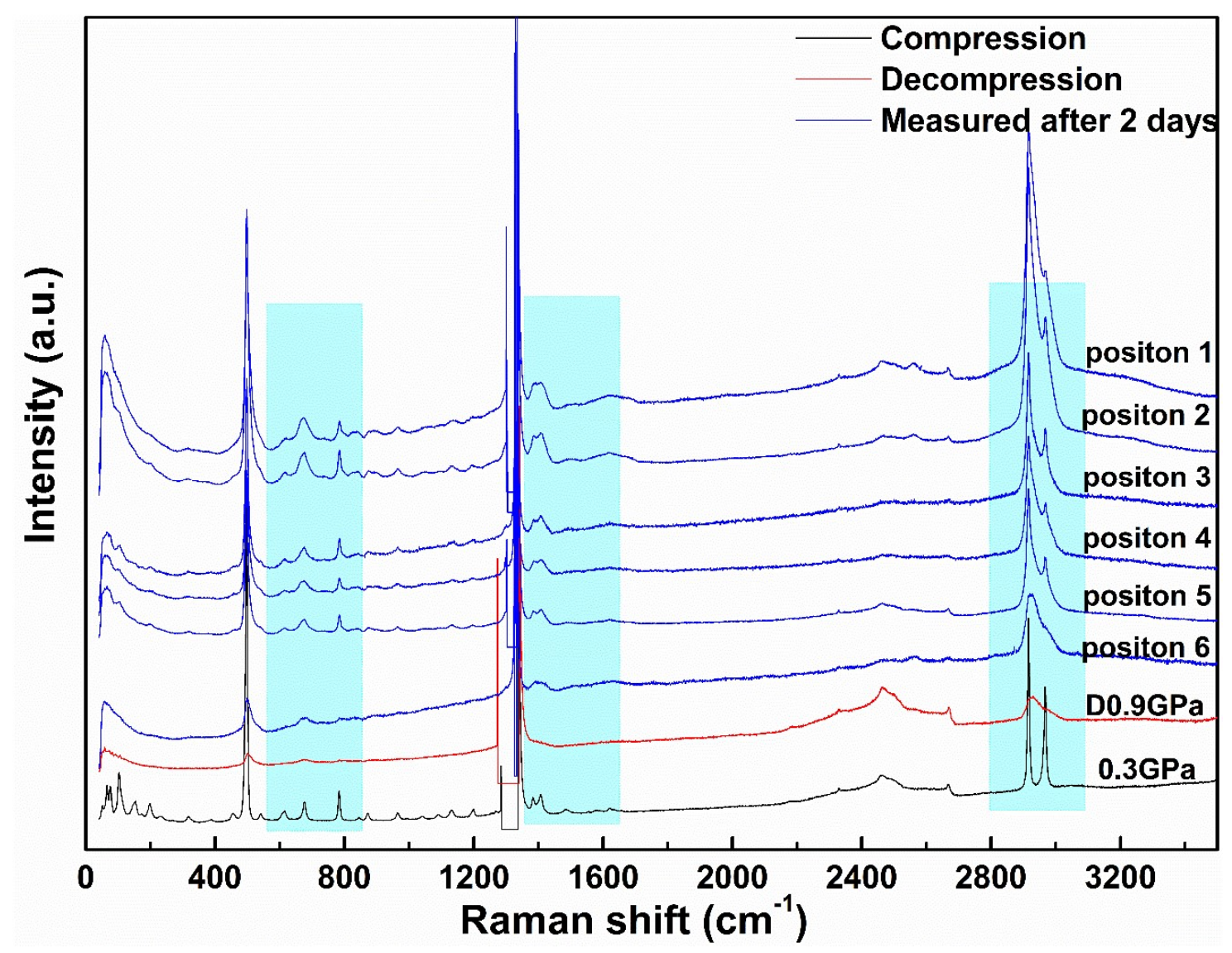

Figure S6. Comparison among the Raman spectra of the L-cystine sample after compressing to $0.3 \mathrm{GPa}$ (black curve), decompressing from $52.0 \mathrm{GPa}$ down to $0.9 \mathrm{GPa}$ (red curve), and $48 \mathrm{~h}$ later after full decompression to ambient pressure (blue curves). In the latter case, the spectra were measured at six different positions $(1-6)$ of the sample. The sky-blue areas highlight the band differences. 

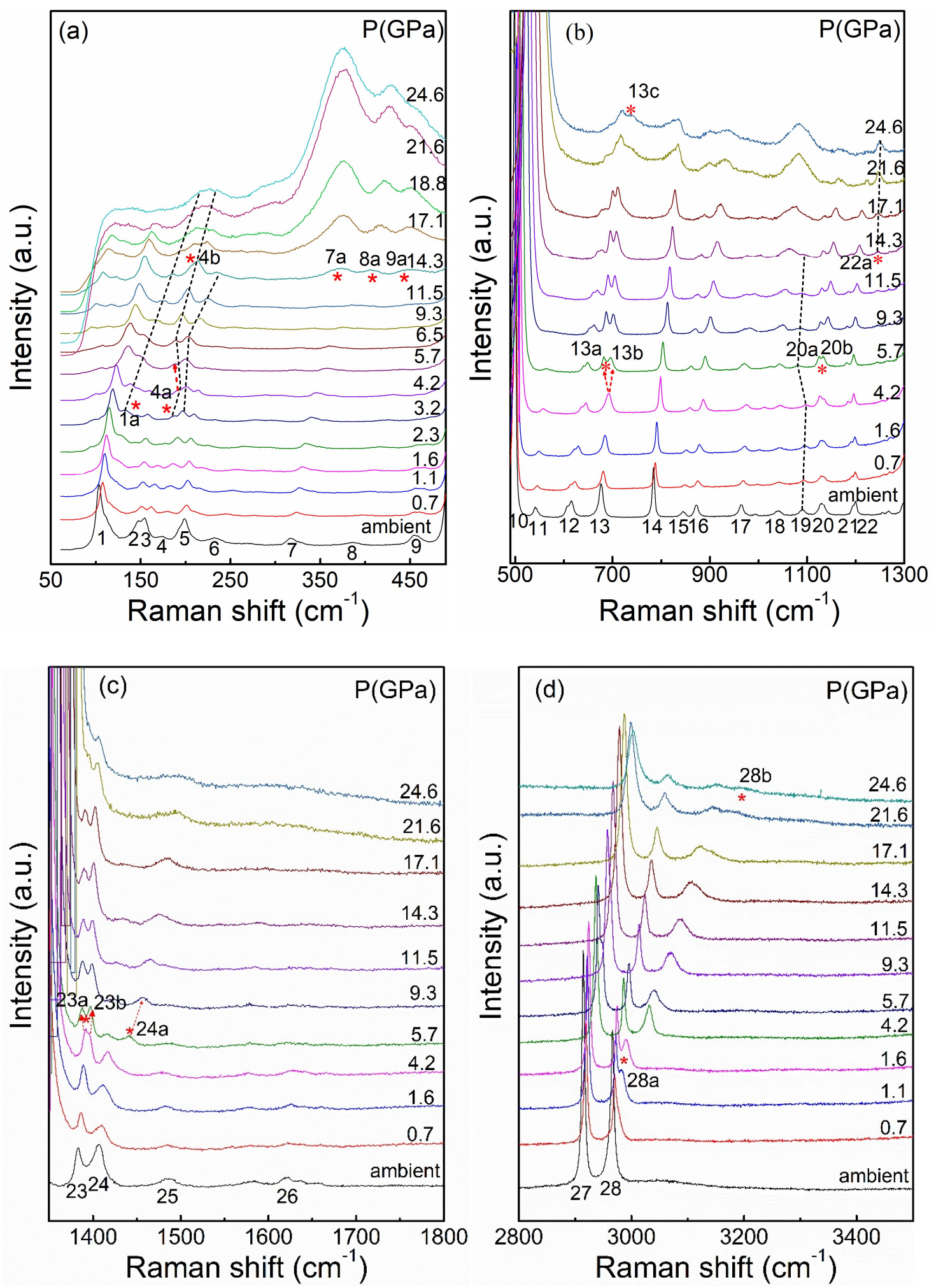

Figure S7. Numbered Raman bands of L-cystine in different wavenumber regions: (a), $50-490$ $\mathrm{cm}^{-1}$, (b), $490-1300 \mathrm{~cm}^{-1}$, (c), $1350-1800 \mathrm{~cm}^{-1}$, and (d) $2800-3500 \mathrm{~cm}^{-1}$. 


\section{References:}

(1) Lutterotti, L. Maud Tutorial-Instrumental Broadening Determination. Dipartimento di Ingegneria dei Materiali, Università di Trento 2006, 38050.

(2) Balzar, D.; Audebrand, N.; Daymond, M. R.; Fitch, A.; Hewat, A.; Langford, J. I.; Le Bail, A.; Louër, D.; Masson, O.; McCowan, C. N. Size-Strain Line-Broadening Analysis of the Ceria Round-Robin Sample. J. Appl. Crystallogr. 2004, 37, 911-924.

(3) Young, R. A. The Rietveld Method. Oxford University Press: 1993.

(4) Gražulis, S.; Chateigner, D.; Downs, R. T.; Yokochi, A. F. T.; Quirós, M.; Lutterotti, L.; Manakova, E.; Butkus, J.; Moeck, P.; Le Bail, A. Crystallography Open Database-an Open-Access Collection of Crystal Structures. J. Appl. Crystallogr. 2009, 42, 726-729. 